\title{
Estudo Sobre a Constituição de Um Sistema Social Em Ambiente Virtual de Aprendi- zagem
}

Karla Marques da Rocha

Orientador: Profa. Dra. Margarete Axt

Data de defesa: 03 de novembro de 2008

Nas últimas décadas, as mudanças sociais, econômicas, políticas na cultura, ciência e, especialmente no campo da tecnologia, vêm revolucionando as formas de comunicação e de relacionamento entre as pessoas. Algumas mudanças se configuram devido ao desenvolvimento tecnológico, especialmente no apoio à educação. A Educação a distância, na qual os processos de ensino e aprendizagem ocorrem com a utilização de meios e tecnologias de informação e comunicação, favorece o surgimento de novos espaços de convivência. Esta tese propõe uma visão de comunidade em ambiente virtual de aprendizagem específico, observando seu processo de constituição. Tendo como referência a teoria da Biologia do Conhecer, de Humberto Maturana, foi estudada a rede conversacional que se constituiu na instância do "correio", ferramenta de comunicação em um Curso de Especialização. Buscou-se identificar o acoplamento estrutural entre os participantes do curso no espaço coordenação/tutoria e o ambiente virtual de aprendizagem e, a partir deste acoplamento, a constituição de um sistema social. Para tal, foram mapeadas as mensagens produzidas por meio da ferramenta "correio", do ambiente, através de categorias, o que permitiu identificar tanto o acoplamento dos participantes do curso com o ambiente como a constituição do próprio sistema social, enquanto uma comunidade de aprendizagem.

Palavras-chave: Ambiente de aprendizagem - Ambiente virtual. Informática na educação. Tecnologia da informação e comunicação. Rede de conversação. Maturana, Humberto. 